\title{
THE BENEFITS OF SCHOOL FEEDING PROGRAMME IN WESTERN ZAMBIA
}

\author{
Constance Sitali ${ }^{1}{ }^{\boxplus}$, Oswell Chakulimba ${ }^{2}$, Sophie Kasonde-Ng'andu ${ }^{2}$ \\ 1Kwame Nkrumah University -Kabwe, Zambia \\ 2 University of Zambia- Lusaka, Zambia
}

DOI: https://doi.org/10.29121/granthaalayah.v8.i9.2020.1412

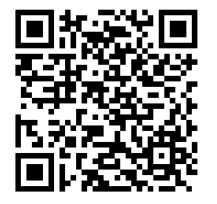

Article Type: Research Article

Article Citation: Constance Sitali, Oswell Chakulimba, and Sophie Kasonde-Ng'andu. (2020). THE BENEFITS OF SCHOOL FEEDING PROGRAMME IN WESTERN

ZAMBIA. International Journal of Research -GRANTHAALAYAH, 8(9), 176-182.

https://doi.org/10.29121/granthaa layah.v8.i9.2020.1412

Received Date: 6 September 2020

Accepted Date: 30 September 2020

Keywords:

School Feeding Programme

Benefits

\section{ABSTRACT}

The study sought to establish the benefits of school feeding programme (SFP) in Western Zambia. It also brought out the challenges encountered in the execution of the programme. This article is an extract from one of the objectives of ongoing study. School feeding entails the distribution of food commodities to children who attend school. The commodities may be locally grown and purchased or contributed by international donor community. The food may be consumed by the learners in school. In other settings, it may be given as take-home ration for consumption by the families that regularly send their children to school. The study employed a descriptive survey research design to collect, analyse and interpret both quantitative and qualitative data from 415 respondents. The results of the study showed that the school feeding programme is an intervention which has enormous education benefits; equitable access to education, increased school enrolment, improved attendance, punctuality and academic performance. Other benefits include: health and nutrition, social protection, parent involvement, and opportunities for local farmers. However, challenges were also reported; there were some possible negative attributes to the increase in the enrolment rates, that is, the educational quality may be compromised if the number of learners exceeds available resources such as desks, text books, teachers, and irregular supply of food to schools. The study recommended that plans and measures should be put in place by the government, relevant ministries and development partners on how to increase existing human, physical, and financial resources for the school feeding programme to be effective and sustainable. SFP should also be decentralized to the schools and community levels with more support from provincial offices to ensure a more effective school feeding programme.

\section{INTRODUCTION}

School Feeding Programme (SFP) can be broadly defined as the provision of food to Primary day-schoolchildren (WFP 2012). It has been introduced in many developed and developing countries worldwide to address the issue of poverty, and to enhance the challenges of low school enrolment, attendance and poor academic performance among others (UNICEF 2005). According to United Nations' World Food Programme (2010), in developing countries, almost 60 million children go to school hungry every day and about 40 percent of them in Africa. Working with

(C) 2020 The Author(s). This is an open access article distributed under the terms of the Creative Commons Attribution License, which permits unrestricted use, distribution, and reproduction in any medium, provided the original author and source are credited. 
national governments, local authorities and Non-governmental Organisations (NGOs), World Food Progamme (WFP) use food to encourage children to school where enrolment, attendance and performance ratios had been low. The entry point is food insecurity which results among other things high levels of poor school attendance, and a variety of the negative coping mechanisms such as taking children out of school to search for food or income Koethe,J R and Heimburger,D C , (2010). It is believed that this would prevent short term hunger, encourage children to continue attending the school and enhance their concentration and academic performance. However, the aim of school feeding differs in its design, purpose and implementation from country to country, and also socio-economic situations of the communities in which school feeding is offered. Learners can be fed either in school, where meals are prepared and served during the school day or it may be given as take- home ration (THR) for consumption by a family that may regularly sends children to school. According to Bundy et al, (2009), the dissimilarity on purpose is determined by the need, resources and policies in the given country context.

Ahmed (2004) submits that an empirical evidence of the benefits of school feeding programme on educational outcomes proves that the programme increases school enrolment and attendance by reducing drop-out. This view was supported by Finan (2010) who argues that food acts as a strong incentive for children to enrolment. A study conducted by Kremer and Miguel (2007) showed that provision of school meals reduces the net cost of sending children to school, more especially in large families thereby increasing their enrolment to education.

Researchers have linked the provision of school meals to increase school attendance among learners. A study done in India has shown that the school feeding programme has indeed increased attendance of learners in primary schools (Gentilin, 2016). Additionally, Greenhalgh, et al. (2007) found those learners who received a school meal in low- and middle-income countries showed higher attendance levels compared to those in high income countries. Furthermore, school feeding programme had been cited to have positive impact on time management in school through increased punctuality and regular attendance (Donald, 2005).

In Zambia, the school feeding intervention was introduced in 2003 after the country experienced the food and drought crisis of 2002. The government in partnership with the World Food Programme (WFP) embarked on a pilot project of school feeding in some schools situated in the most drought-prone and food- insecure districts with low educational indicators. Children in all targeted schools received porridge upon arrival at school every day. After years of successful implementation; the programme was scaled up, to other parts of the country. However, since the school feeding programme was initiated, little has been done to establish the benefits of the programme. Therefore, the study intended to find out the benefits of the programme in Western Zambia.

\section{MATERIALS AND METHODS}

A descriptive survey design was employed to establish the benefits of school feeding programme in Western Zambia. This design was preferred because it allows the researcher to gather information, analyse, and interpret data for the purpose of clarification (Orodho, JA 2008). Quantitative and qualitative methods were used. The rationale for using both methods was that neither quantitative nor qualitative was adequate in itself to capture and reveal the details of the phenomenon of the study. Simple random sampling and purposive sampling procedures were used to select 415 respondents. The researcher relied a great deal on the questionnaire, interview and focus group discussion guides which were supplemented by secondary data sources. Different sets of questionnaires were administered to head teachers, teachers, district education planners and WFP Provincial officer while interviews with parents and focus group discussions with learners in each of the schools. A questionnaire offers considerable advantages as being administered because it presents a stimulus to a large number of people simultaneously, and provides the researcher with a relatively easy accumulation of data. Observations were also carried out in the field and this created opportunities to obtain certain critical data in natural settings, and also provided an opportunity to triangulate data gathered through questionnaires, interviews and focus group discussions. Quantitative data were analysed used descriptive statistics while qualitative data were analysed used the thematic approach. Instruments were used to measure both objective and subjective phenomena, and provide information that was trustworthy and credible. 
The Benefits of School Feeding Programme in Western Zambia

\section{PRESENTATION OF FINDINGS}

This part of the study was aimed at finding out from the head teachers, teachers, parents, district education planners, WFP Provincial officer and learners on the benefits of school feeding programme in Western Zambia. This was to address one of the research questions; "what benefits does school feeding bring to the poor and marginalised in society?".

A total of 415 respondents; 27 head teachers, 108 teachers, 108 parents, 9 district planners 162 learners and 1 WFP officer were asked to state the benefits of the school feeding programme. The study findings showed that all the 415 participants representing 100 percent acknowledged that school feeding programme had multiple benefits despite some noted operational challenges.

Head teachers and teachers highlighted some benefits of school feeding programme such as an increase in school enrolment, reduction in truancy, improved punctuality and academic performance. This is what the headteachers and teachers had to say:

"Before the implementation of school feeding programme, school headteachers used to persuade parents to enrol their children in school, but now it appears all parents are motivated to have their children enrolled, due to school feeding programme mainly."

"Ever since the school feeding programme was in progress, we have observed an increase in the number of learners attending school. School feeding programme help in providing food to learners hence encouraging parents to ensure that their children attend school regularly."

"Since the provision of meals, the majority of the learners are always punctual for classes, and even class head count is almost a hundred percent."

Furthermore, the research findings also captured other positive outcomes which the respondents linked to school feeding programme benefits; example of which were issues to do with the improved nutritional status of learners that seem to have improved learning and a decrease in morbidity among school going children. Further, argued that some learners leave for school hungry and after a few hours they used to complain of different ailments such as stomach aches and headaches but those complaints were reduced after introduction of the school feeding programme. Some teachers observed that this well-being by most learners resulted in improved attendance and raised punctuality leading to increase time learners spent in school.

Additionally, head teachers and teachers revealed the benefit of school feeding programme when linked to the main stream curriculum; its priorities experiential education integrates several subject areas, and extend its influence on the whole school, the family and the community. However, it was also noted that while school feeding programme has led to an increase in enrolment and attendance, this increases the likelihood that educational quality will be compromised if the number of learners exceeds available resources such as desks, text books and teachers.

Some district planners noted that school feeding was acting as an equalizer in that Poor households were then able to send their children to school where they received some foods stuff. Other respondents observed that, school feeding acts as a catalyst for household food security and income, by providing school meals at school and coupled with a take- home ration for other family members, helped free up household income that would have otherwise been used for food purchases. This response was in line with what the WFP officer stated;

"One of the benefits of school feeding is to narrow the hunger gaps between children from hunger-stricken households, and the food secure households because both children receive one adequate meal per day."

The WFP provincial officer also revealed the benefit of school feeding programme when linked to agriculture. This is what was noted:

"Linking school feeding programme to the agriculture sector benefit the entire community through stimulating local market and facilitating agricultural transformation; this can help to create predictable and structured markets for local produce where children should be fed on locally grown foods."

In an interview with parents, it was mentioned that the programme has resulted in improved collaboration and participation between school administration and the community, for instance, parents were volunteering to prepare meals, collect water and in some cases offer their ox-carts for free to ferry firewood or even collect foods stuff for the programme to continue.

One parent had this to say:

"School feeding programme provides us with an opportunity to participate in the education of our children and always available to work with the school management when need arises." 
However, some parents disclosed that despite willing to help in preparing food for children, schools lack basic equipment and utensils necessary for preparing and serving meals.

Some parents disclosed that the performance of their children had improved since the commencement of school feeding programme. They had this to say:

"The school feeding enables our children cope with the school work and other school manual activities, especially that most of them are coming from hunger-stricken homes,"

The findings from the focus group discussions with learners revealed that, school feeding attracted more children to be enrolled and motivated many learners to be attending classes regularly, and that their friends who go to other schools where this programme was not implemented were seeking transfers to move to schools where the programme was implemented.

\section{DISCUSSIONS OF THE FINDINGS}

When the participants were asked on the benefits of school feeding programme, it was established that there were a number of benefits associated with the programme. All the participants' responses revealed that providing learners with a meal a day was the first priority benefit of school feeding programme. The results of the study showed an increase in school enrolment. The fact that the learners would be provided with at least one meal per day could lead to the enrolment increase. This is consistent with the findings by Ahmed (2004) who argued that SFP generally has positive effects on school enrolment. Furthermore, this was supported by the WFP (2004) that one of the positive effects associated with serving meals at school is the increase in enrolment rate in schools of under privileged children. However, the researcher had a view that some other factors could have contributed to that, for instance, in 2009 the government of Zambia introduced the free primary education (FPE) programme in schools which could have resulted in the increase rate in school enrolment. Additionally, there were some possible negative attributes to the increase in the enrolment rates; that is, the educational quality was to be compromised if the number of learners exceeds available resources such as desks, text books and teachers.

The findings further revealed that the school feeding programme was very much associated with better attendance. The majority of the participants highlighted that the SFP had contributed to regular attendance of learners. This is in agreement with the findings by the WFP (2004) that School Feeding Programme is considered as instrument which powerfully motivates even the poor children to attend school as they are guaranteed a meal at school. Some participants mentioned that the SFP promoted punctuality of the learners at school. This view was supported by Donald (2005) who recommended that school feeding programme has positive impact on time management in schools through enhanced punctuality and attendance. Their findings were consistent with the results of this study as the teachers and parents indicated that school feeding programme promoted punctuality and attendance rates in the schools. The results from the focus group discussions also confirmed that the SFP promoted regular attendance and punctuality.

From academic perspective, the findings indicated that school feeding programme improved learners' academic performance; learners' cognitive functions were enhanced. School feeding contributes to children's readiness to learn and ability to participate in their educational process. This is similar to the observation by the WFP (2010) that school feeding reduces hunger among the learners which improve their ability to concentrate in the classroom. Gougeon et al (2011) also argued that attending to temporary hunger during school hours plays a crucial role in improving school results as learners' concentration span and their performance are negatively affected if they stay without food for longer periods. It was further established that an intervention of a school feeding to underfed learners resulted in improved nutrition and health; hence better performance. On the same note, Briggs (2003) suggested that the intake of a high-quality diet is vital for improved memory functions which results in enhanced education effects. It has been revealed that due to the improved concentration of the learners, teacher-learner interaction was observed and active participation of learners were enhanced which resulted in increased pass rates. However, it has to be admitted that so many factors could influence the academic performance of learners in schools such as availability of teaching and learning materials, conducive learning environment, and quality teaching among other things.

The analysis of the data indicated that head teachers and teachers concurred that the school feeding was acknowledged for providing meals to learners and meeting educational objectives probably because most of these schools were found in food insecure areas where poverty and hunger were life threatening as confirmed by the 
findings from focus group discussions. These findings are in agreement with Gelli (2010) who advocated that school feeding promotes educational objectives, health and community development.

Some participants brought up other benefits from the programme that go down to households and communities. For instance, the district planners who felt that one of the benefits of school feeding was that of take-home ration. It has an economic benefit to families, in that; it frees some income that could have been used to buy food to meet other household needs or other school requirements. Similarly, the programme, puts the 'have not' and 'haves' on the same level because their children were able to attend classes regularly, which may not have been possible without the programme. This leads to pupils progressing well in their education, acquire skills and subsequently contribute to national development, and pay taxes to government for development. The programme also promotes human capital development in the long run and help to break inter-generational cycles of poverty and hunger.

From the responses presented, it was also clear that school feeding programme had health benefits which included reduction or alleviation of hunger symptoms in the learners and helped them to be physically fit during school-days. This finding was in line with the views of WFP (2004) that school feeding programme is a mechanism that provides health benefits to the vulnerable population found in areas and communities with severe food shortage. Head teachers and teachers amplified that school feeding improved nutritional status of pupils that seem to have improved learning and a decrease in morbidity among school going children. It was also observed that this well-being by most learners resulted in improved attendance and raised learners class punctuality leading to increase time learners spent in school.

From the responses presented, it was noted that the programme has resulted in improved collaboration and participation between school administration and the community. This is in line with Cole (2007) who also added to say community participation is considered necessary to get community support for educational planning and development. Therefore, community participation plays an essential and longstanding role in promoting quality of life. Furthermore, increased communication between communities, parents and teachers is enhanced which in turn has favourable benefits for the quality of education and nutritional awareness as parents become sensible with what goes on at the school. Preparation of meals is done at the schools with the local communities being involved in the preparation of meals. This depends on the availability of volunteers. School feeding programme affords parents an opportunity to become more aware of what goes on at schools and help build love, appreciation and the value of education for parents, and the community at large.

The research findings discovered that linking school feeding programme to the agriculture sector has direct economic benefits and can potentially benefit the entire community as well as the children. This is similar to the views of Sumberg and Sabates-Wheeler (2011), that linking school feeding to local agricultural production can help the sustainability of the programme and create predictable and structured markets for local produce. school feeding programme creates increased demand for food commodities which stimulates increased local food production and translates into sustainable nationally owned and effective home-grown school feeding.

The findings of the study showed that school feeding acts as a catalyst for household food security and income, by providing school meals at school and coupled with a take home ration. School feeding programme has proved to be an essential instrument in social protection. This is in accordance with the World Bank (2009), who stated that school feeding is the most widely used safety net in the world especially, in low- and middle-income countries. Oftentimes, school feeding programme is classified as social safety nets, that is, as a means to provide assistance to poor and food insecure people, and predominantly schoolchildren. In emergency and crisis situations the provision of food to address food insecurity might still be the main objective of school feeding programme. However, nowadays, most school feeding programme, particularly national programme is implemented with the objectives of positively impacting various educational, health and nutrition related indicators of school children.

School feeding, particularly when integrated into a national social protection scheme, can contribute to the four dimensions of social protection that provides relief and alleviates poverty and hunger; it helps people cope with shocks and avoids the adoption of negative coping strategies, such as removing children from school, during the times of economic stress or crisis. It helps enhance the incomes and human capital needed to overcome poverty and build resilience and future livelihoods by facilitating education, health and nutrition outcomes for beneficiary families and it has the potential to transform local economies, social relations and behaviours. In a broad developmental sense, school feeding programme can make significant contribution towards achieving several of the sustainable development Goals (SDGs), particularly in relation to hunger, education, health and gender equality. 


\section{CONCLUSION}

In this article, an attempt was made to establish the benefits of school feeding programme in Western Zambia. A number of benefits have been associated with school feeding programme which includes equitable access to education, increased school enrolment, improved attendance, punctuality, academic performance, health and nutrition, social protection, parent involvement, and opportunities for local farmers. School feeding programme which is linked with the procurement of food from local small-scale farmers and involved community participation is expected to result in more sustainable, and community owned school feeding programme. The potential education benefits of the school feeding programme are a strong justification for Zambia and the Ministry of General Education to implement and own the programme, while these same education outcomes contribute to the incentive compatibility of the programme for social protection. Furthermore, school feeding programme has multiple benefits and important tool to reach the most vulnerable children living in highly food-insecure areas with low educational indicators.

\section{RECOMMENDATIONS}

Based on the findings of the study, the following were some of the recommendations;

- The study recommended that plans and measures should be put in place by the government, relevant ministries and development partners on how to increase existing human, physical, and financial resources for the school feeding programme to be sustained.

- It was also suggested that school feeding programme should be decentralised with more support from provincial offices to ensure a more effective and sustained programme.

\section{SOURCES OF FUNDING}

This research received no specific grant from any funding agency in the public, commercial, or not-for-profit sectors.

\section{CONFLICT OF INTEREST}

The author have declared that no competing interests exist.

\section{ACKNOWLEDGMENT}

None.

\section{REFERENCES}

[1] Ahamed, A. U. (2004). Impact of Feeding Children in School: Evidence from Bangladesh, International Food Policy Research Institute (IFPR) Washington, DC: Mimeo.

[2] Briggs, B. (2008). School Feeding Programmes: Summary of best literature \& best practices. Village Hope Technical Report 6. pp 1-3.

[3] Bundy, D., Burbano, C., Grosh, M., Gelli, A., Jukes, M. \& Drake, L. (2009). Rethinking School Feeding: Social safety nets, child development and the education sector, Washington, DC: World Bank.

[4] Donald, B. (2005). School Health and Nutrition: Policy and Programme. Food and Nutrition Bulletin, 26(2)186-192 (1).

[5] Finan, Timothy. (2010). Impact Evaluation of WFP School Feeding Programme in Kenya: A Mixed-Methods Approach. Rome: World Food Programme.

[6] Gelli, A., Neeser, K \& Drake, L. (2010). Home Grown School Feeding: Linking small holder agriculture to School Food Provision. In PCD Working Paper no.212. London: Partnership for Child Development. 
[7] Greenhalgh, T., Kristjansson,E.,\& Robinson, V. (2007). Realist review to understand the efficacy of school feeding programmes. BMJ, 335(7625), 858-861. Hunger in America: 2012 United States Hunger and poverty facts. World Hunger Education Service.

[8] Kremer, M \& Migues, E. (2007). Incentives to Learn, USA: Havard University Press Cambridge.

[9] Orodho, J. A. (2008). Techniques of Writing Research Proposal and Report in Education and Social sciences, Nairobi: Kenezja Publisher.

[10] Sumberg, J. \& Sabates-Wheeler, R. 2011. Linking agricultural development to school feeding in sub-Saharan Africa: Theoretical Perspective Food Policy.

[11] UNICEF (2005) The State of the World's Children Report. Excluded and Invisible. New york: UNICEF.

[12] WFP (2010). Home Grown School Feeding: A Framework to Link School Feeding with agricultural Production. Rome: WFP.

[13] WFP Centre of excellence against Hunger (2012). Annual Report 2012. Brasilia: WFP. 